\title{
Piezas metálicas de la Edad del Bronce en la Meseta: puntas de flecha triangulares con pedúnculo y aletas
}

\author{
amparo Hernando Grande
}

Como miembro del Departamento de Prehistoria e Historia antigua de la Universidad Nacional de Educación a Distancia del que el Dr. Ripoll ha sido su Director durante un largo período de tiempo, es nuestra intención colaborar con estas breves páginas en el homenaje merecido que sus amigos, colegas y alumnos le ofrecemos, con el deseo de que su labor cientifica e investigadora dentro de la Prehistoria continúe con la misma intensidad que hasta ahora.

Son muchas las manifestaciones arqueológicas, que día a día y dentro del ámbito cultural de la Edad del Bronce, nos van proporcionando un conocimiento más profundo de ese período, en el marco geográfico de la Meseta peninsular, lo que nos permite, no solo diferenciarla de otras áreas peninsulares más conocidas (Bronce del Suroeste, Bronce Valenciano, etc.), sino también el poder individualizarla con entidad propia dentro del panorama cultural de la Edad del Bronce. Todo lo cual, pone de manifiesto la arbitrariedad de aquellas consideraciones que presentaban a la Meseta como una zona relegada y adormecida culturalmente durante esta Edad, esperando a recibir continuamente las influencias que le llegaban procedentes de los "potentes" núcleos culturales que se estaban desarrollando en otras zonas extrameseteñas.

Dentro de esas manifestaciones que de forma efectiva nos están hablando del dinamismo cultural, semejante al de otras áreas peninsulares, que mantuvo la Meseta durante la Edad del Bronce, vamos a centrar nuestra atención en un tipo de piezas metálicas, que se encuentran bien 
representado en yacimientos meseteños del II milenio: las puntas de flecha triangulares con pedúnculo y aletas.

Conocemos la existencia, no solo de un número considerable de yacimientos correspondientes a este momento, dentro del marco geográfico de las dos Submesetas, de los cuales proceden flechas de las características que estudiamos; sino que igualmente y en el mismo marco geográfico, son abundantes los hallazgos aislados, casuales o desconocidos de esas piezas, de las que únicamente conocemos el nombre de los lugares de donde proceden respectivamente. Nuestra atención irá dirigida especialmente a la puntas de flecha del primer supuesto, es decir, a aquellas que están presentes, se constatan y proceden de yacimientos, ya que evidentemente en estos casos la punta queda exactamente encuadrada en un tipo de yacimiento concreto e igualmente asociada y relacionada con el resto de los materiales, que conforman el contexto general del mismo, permitiéndonos la ubicación temporal y espacial de la pieza (mapa 1).

Desde el punto de vista morfológico, todas las puntas de flecha presentan rasgos comunes: su hoja es triangular, portan pedúnculo pronunciado, es decir, bien diferenciado de la hoja, y aletas laterales; éstas pueden aparecer en algunos casos de forma marcada, y en otros casos de forma incipiente o iniciada. Éste es un rasgo diferenciador meramente morfológico, sin connotaciones culturales y cronológicas, ya que incluso en un mismo yacimiento pueden hallarse juntas flechas con aletas de las dos formas. Sí podría considerarse como un rasgo morfológico de caracter funcional, pues evidentemente la pronunciación de las aletas originaría en el objetivo un mayor impacto desgarrador que aumentaría con el intento de extracción de la punta.

Dentro de los yacimientos que podemos encuadrar en la Submeseta Sur, en los cuales se hallan presentes puntas de las características que estudiamos, está el de La Peñuela, en la provincia de Albacete, del cual procede una flecha de cobre con aletas laterales incipientes que mide $6,6 \mathrm{~cm}$ de longitud y $1,7 \mathrm{~cm}$ de anchura máxima (fig. 1, núm. 1). Este yacimiento fué considerado por su autor como argárico y de tipo sepulcral (S. Jiménez 1947: 7-17 y 148: 96-110). Con posterioridad a esta primera interpretación fue considerado como yacimiento tipo "Motilla", encuadrandose en el Bronce Medio Meseteño (Najera et alii 1979: 21).

Otra punta semejante procede del yacimiento de La Dehesa de Caracolares, también en la provincia de Albacete, es de cobre y mide $8,8 \mathrm{~cm}$ de longitud y $1,5 \mathrm{~cm}$ de anchura máxima, presenta aletas latera- 


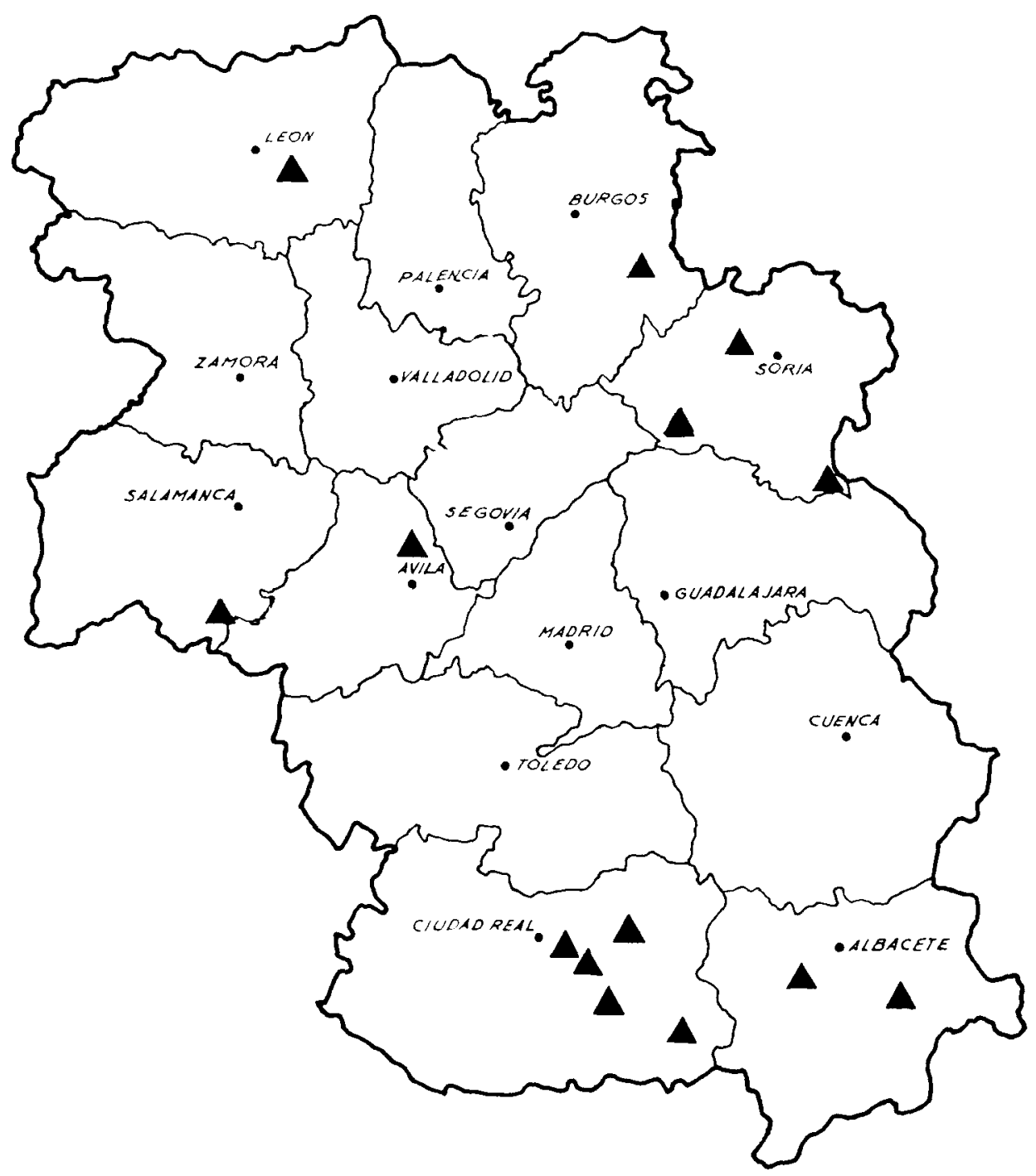

PUNTAS DE FLECHA

TRIANGULARES

Mapa 1. Dispersión puntas de flecha triangulares con pedúnculo y aletas. 

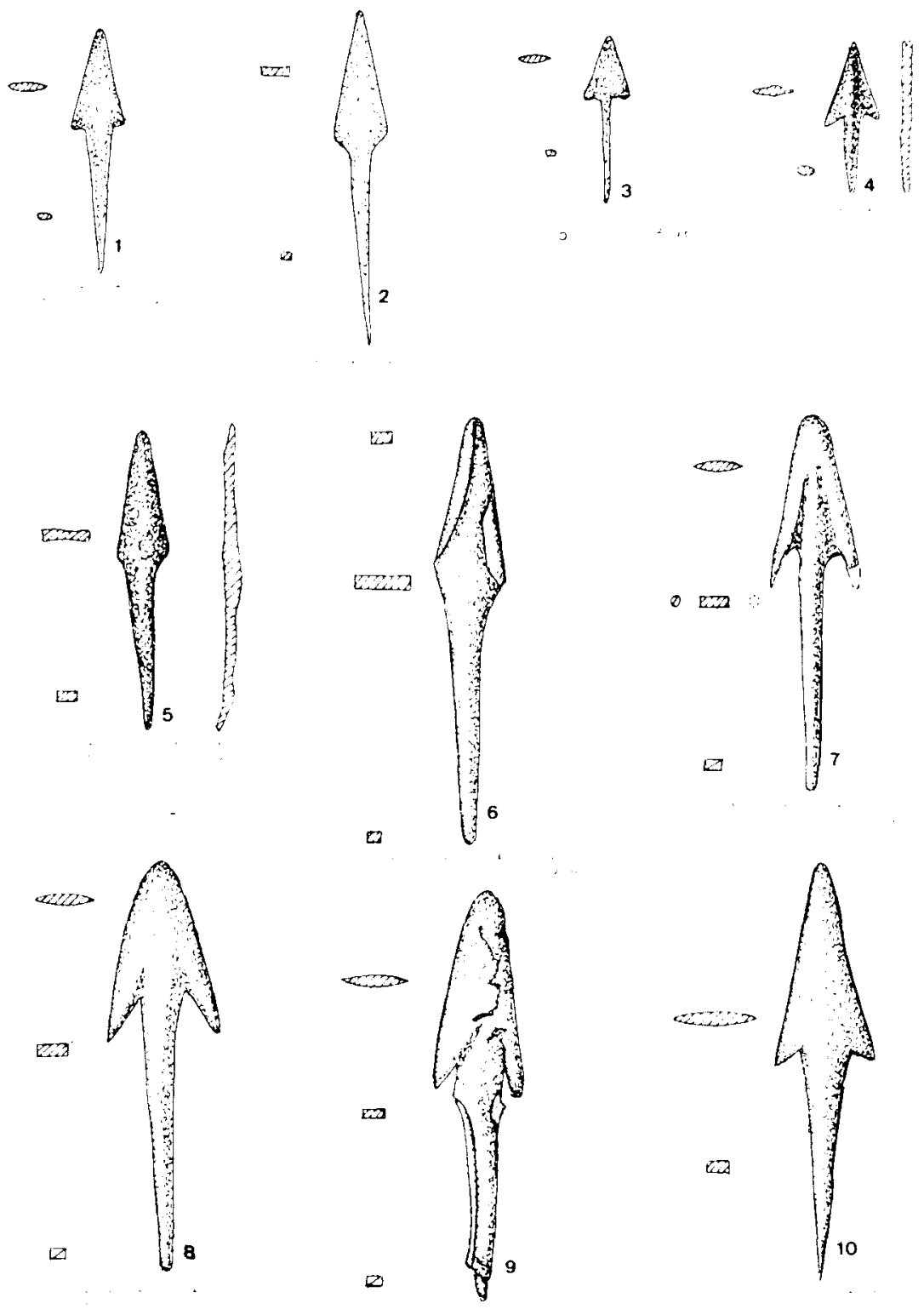

Fig. 1. Número 1: Cerro de La Peñuela (Albacete). Número 2: Dehesa de Caracoles (Albacete). Número 3: Motilla de Los Palacios (Ciudad Real). Número 4: Motilla del Azuer (Ciudad Real). Número 5, 6, 7, 8, 9 y 10: Cerro de la Encantada (Ciudad Real). 
les iniciadas (fig. 1, núm. 2). Yacimiento considerado por su autor como argárico (S. Jiménez 1948: 96-110).

Son varios los yacimientos que encontramos en la provincia de Ciudad Real, que nos han proprocionado ejemplares del tipo que estudiamos. Asi, una punta de estas características procede de la Motilla de Los Palacios, es de coore, con las aletas laterales iniciadas y mide $5 \mathrm{~cm}$ de longitud y $1 \mathrm{~cm}$ de anchura (fig. 1, núm. 3). Este yacimiento, según sus autores, corresponde al Bronce Pleno 1500-1300 a. de C. (Najera et alii 1977: 251).

Otra punta de estas características procede de la Motilla del Azuer, yacimientos del mismo tipo que el anterior, es una flecha de cobre, que presenta en este caso las aletas laterales pronunciadas, y mide $5 \mathrm{~cm}$ de longitud y $1,5 \mathrm{~cm}$ de anchura (fig. 1, número 4). Este yacimiento como el anterior lo sitúan sus autores en el Bronce Pleno, y concretamente la punta de flecha en un Bronce Antiguo-Pleno (Najera et alii 1977: 251 y 1979: 21).

Continuando con yacimientos de la provincia de Ciudad Real en los cuales se hallan presentes puntas del tipo que estudiamos, debemos citar el del Cerro de La Encantada. Entre el abundante material metálico que este yacimiento ha proporcionado, una buena parte de él lo configuran las puntas de flecha de estas características. Dos de ellas, con aletas laterales incipientes fueron halladas en el estrato II de dicho yacimiento, midiendo respectivamente $6,7 \mathrm{~cm}$ de longitud y $1,3 \mathrm{~cm}$ de anchura (fig. 1 , núm. 5) y $8 \mathrm{~cm}$ de longitud y $1,5 \mathrm{~cm}$ de anchura (fig. 1, núm. 6). El resto de las puntas, siete en total, poseen las aletas laterales muy pronunciadas, del estrato I del yacimiento proceden dos con esta característica, siendo sus medidas respectivas de $6,7 \mathrm{~cm}$ de longitud y $1,5 \mathrm{~cm}$ de anchura (fig. 1 núm. 7) y $7,7 \mathrm{~cm}$ de longitud y $1,8 \mathrm{~cm}$ de anchura (fig. 1 , núm. 8). Del estrato II del yacimiento proceden cinco puntas de este tipo, que miden: $7,7 \mathrm{~cm}$ de longitud y $1,7 \mathrm{~cm}$ de anchura (fig. 1 , núm. 9); 7,9 $\mathrm{cm}$ de longitud y $1,8 \mathrm{~cm}$ de anchura (fig. 1 , núm. 10 ); $3 \mathrm{~cm}$ de longitud y $2 \mathrm{~cm}$ de anchura (fig. 2, núm. 11); $7,5 \mathrm{~cm}$ de longitud y $1,5 \mathrm{~cm}$ de anchura (fig. 2, núm. 12); y la última punta procedente de La Encantada posee las siguientes medidas: $5,4 \mathrm{~cm}$ de longitud y $1,3 \mathrm{~cm}$ de anchura (fig. 2, núm. 13). Todas las puntas que acabamos de relacionar están fabricadas en cobre. Este yacimiento es enmarcado por sus autores en el Bronce de La Mancha (Nieto y S. Meseguer 1980 y 1983: 9-41).

Otro de los yacimientos de la provincia de Ciudad Real, del cual proceden, igualmente un número considerable de piezas del tipo que 

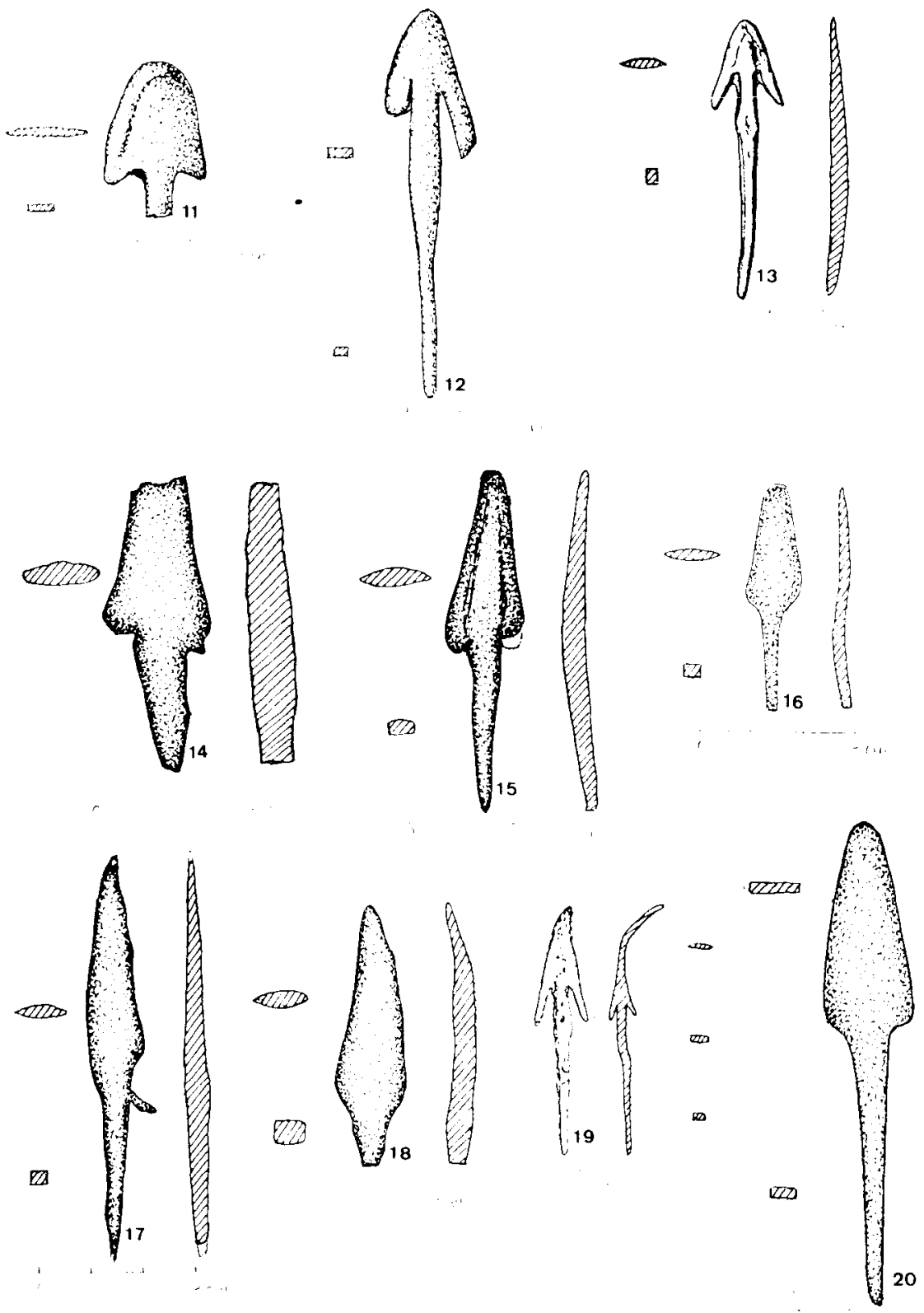

Figura 2. Números 11, 12 y 13: Cerro de la Encantada (Ciudad Real). Números 14, 15, 16, 17 y 18: Motilla de Santa María del Retamar (Ciudad Real). Número 19: Cerro de El Castellón (Ciudad Real). Número 20: Cerro de El Cuco (Cuenca). 
tratamos es el de la Motilla de Santa Maria del Retamar. Dos de ellas presentan las aletas laterales pronunciadas, la primera que se halla fragmentada a la altura de la punta mide $5,2 \mathrm{~cm}$ de longitud y $2 \mathrm{~cm}$ de anchura (fig. 2, núm. 14) y la segunda $6,8 \mathrm{~cm}$ de longitud y $1,6 \mathrm{~cm}$ de anchura (fig. 2, número 15). El resto de las flechas, tres en total, presen$\tan$ las aletas laterales iniciadas o incipientes, y sus dimensiones son: 4,4 $\mathrm{cm}$ de longitud y 1,2 de anchura (fig. 2, núm. 16); $8 \mathrm{~cm}$ de longitud y 1,2 $\mathrm{cm}$ de anchura (fig. 2, núm. 17), esta punta presenta un rasgo morfológico excepcional y diferenciador dentro de las de este tipo, ya que aproximadamente en el comienzo del pedúnculo en su entronque con la hoja presenta un pequeño apéndice, a modo de espolón. La última punta que vamos a tratar procedente de esta yacimiento, presenta el pedúnculo fragmentado y sus medidas son: $5,2 \mathrm{~cm}$ de longitud y $1,3 \mathrm{~cm}$ de anchura (fig. 2, núm. 18). Todas ellas están frabricadas en cobre. Este yacimiento se enmarca en el Bronce de La Mancha (Colmenarejo et alii 1988: 351366).

Otra punta de estas características se halla presente en el yacimiento del Cerro del El Castellón, también en la provincia de Ciudad Real. Es una flecha de cobre, que mide $8 \mathrm{~cm}$ de longitud y $1,4 \mathrm{~cm}$ de anchura, presenta aletas laterales muy pronunciadas y una marcada inclinación en la mitad superior de la hoja, la que puede apreciarse en la sección longitudinal que de esta punta ofrecemos (fig. 2, número 19). Este yacimiento su autora lo encuadra en el Bronce de La Mancha (Poyato EP).

Otro de los yacimientos de la Submeseta Sur, que nos ha proporcionado, concretamente, dos puntas de flecha del tipo que estudiamos es del Cerro de El Cuco, en la provincia de Cuenca. Las dos puntas son de cobre, la primera presenta un largo pedúnculo y aletas laterales iniciadas, mide $9,2 \mathrm{~cm}$ de longitud y $1,6 \mathrm{~cm}$ de anchura (fig. 2, núm. 20). La segunda punta, de dimensiones más reducidas que la anterior, mide 4,85 $\mathrm{cm}$ de longitud y $1,2 \mathrm{~cm}$ de anchura, en este caso las aletas laterales son pronunciadas (fig. 3, núm. 21). Este yacimiento se enmarca en el Bronce de La Mancha (Romero Salas y S. Meseguer 1988: 335-342).

En función de lo que acabamos de exponer, es evidente que todas estas puntas, no solo quedan bien constatadas en yacimientos de habitación o de tipo habitat (cerros y motillas), sino también asociadas y relacionadas al resto de los materiales que de ellos proceden y que conforman sus respectivos contextos culturales.

Siguiendo en el marco geográfico de la Meseta, centraremos ahora nuestra atención en una serie de yacimientos, concretamente de la Sub- 

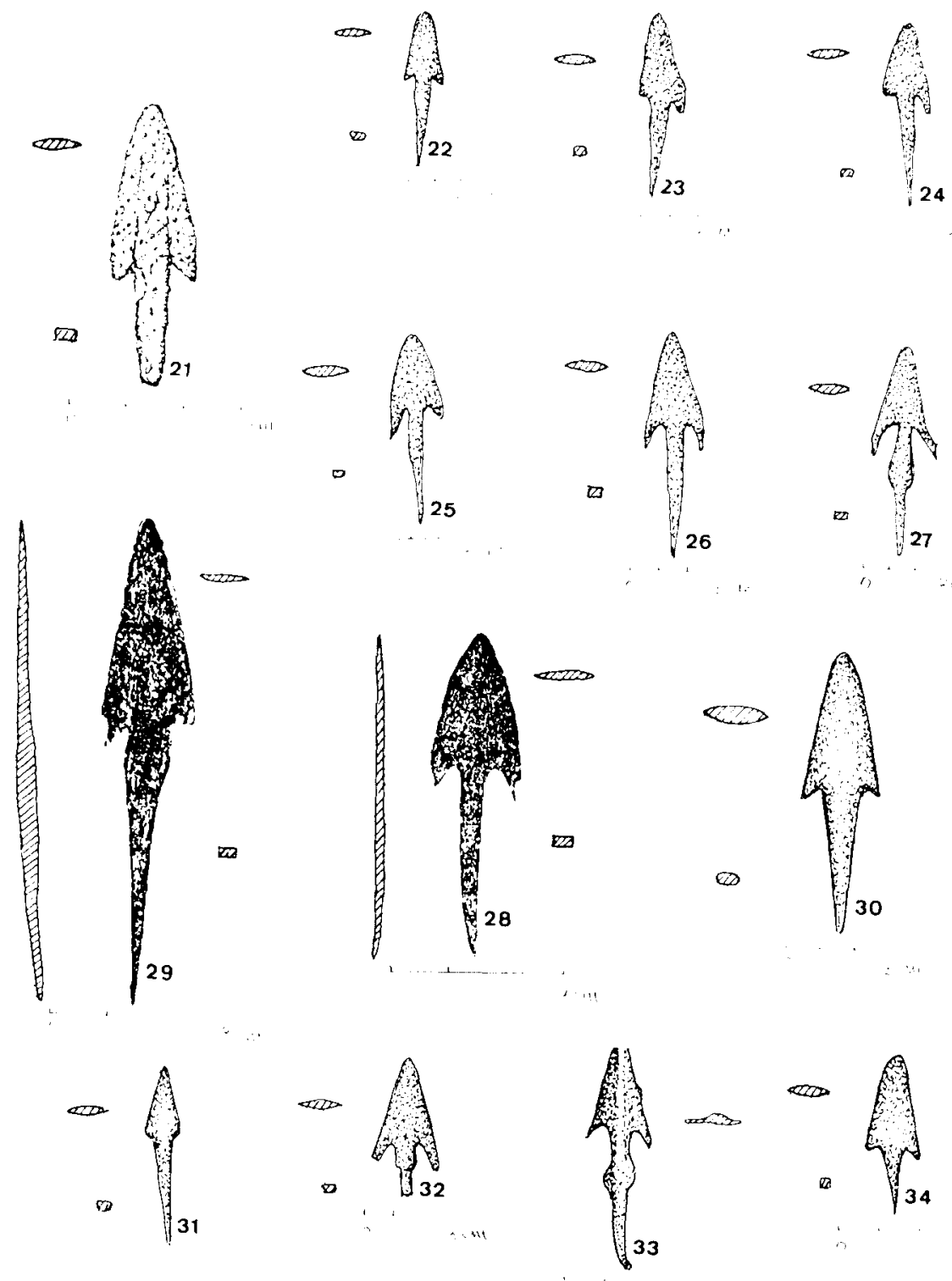

Figura 3. Número 21: Cerro del El Cuco (Cuenca). Número 22, 23, 24, 25, 26 y 27: Cerros de El Castillo (Ávila). Numero 28 y 19: Los Tolmos (Soria). Número 30: Layna (Soria). Número 31: Cerro de El Berrueco (Salamanca). Número 32: Lara (Burgos). Número 33: Villasabariego (León). Número 34: Molino de Garejo (Numancia, Soria). 
meseta Norte de los cuales proceden, igualmente, ejemplares del tipo que tratamos.

Seis puntas de flecha con pedúnculo y aletas pronunciadas están presentes en el Cerro de El Castillo, en la provincia de Ávila. Sus medidas son: $5,8 \mathrm{~cm}$ de longirud y $1,2 \mathrm{~cm}$ de anchura (fig. 3 , núm. 22); 6,5 $\mathrm{cm}$ de longitud y $1,8 \mathrm{~cm}$ de anchura (fig. 3 , núm. 23 ); $7 \mathrm{~cm}$ de longitud y $1,8 \mathrm{~cm}$ de anchura (fig. 3 , núm. 24); $7 \mathrm{~cm}$ de longitud y $1,9 \mathrm{~cm}$ de anchura (fig, 3 núm. 25); $8 \mathrm{~cm}$ de longitud y $2 \mathrm{~cm}$ de anchura (fig. 3 , núm. 26) y la última punta mide $7,8 \mathrm{~cm}$ de longitud y $2 \mathrm{~cm}$ de anchura (fig. 3, núm. 27). En cuanto al material en que están fabricadas, se duda si es cobre o bronce. Para Cabré (Cabré 1931: 285-324) estas puntas son de tipo muy evolucionado dentro de la Edad del Bronce.

En el yacimiento de Los Tolmos, provincia de Soria, fueron halladas dos puntas de las características que estudiamos, en el sector B del mismo. Son de cobre y presentan aletas laterales pronunciadas, sus medidas son: $5,7 \mathrm{~cm}$ de longitud y $2,05 \mathrm{~cm}$ de anchura (fig. 3 núm. 28) y $8,7 \mathrm{~cm}$ de longitud y $1,7 \mathrm{~cm}$ de anchura (fig. 3, núm. 29). Este yacimiento es considerado por su autor (Jimeno 1978: $51-66$ y 1984), como perteneciente al Bronce Medio Meseteño, que correspondería, según él nos confirma, al período comprendido entre el final del Horizonte Campaniforme y el inicio de la fase Cogotas I.

Otro ejemplar se constata en el depósito soriano de Layna, es una punta de flecha fabricada en bronce y con aletas laterales pronunciadas, sus medidas son: $7,9 \mathrm{~cm}$ de longitud y $2 \mathrm{~cm}$ de anchura (fig. 3 , núm. 30). Este depósito es considerado, por diferentes autores, muy cercano al depósito de la ría de Huelva (Taracena 9141: 122; F. Miranda y Balbín 1971: 289-296).

Del Cerro de El Berrueco, provincia de Salamanca, procede una punta de estas caracteristicas. Presenta aletas laterales iniciadas y se duda sobre el material en que está fabricado, cobre o bronce, se desconocen, igualmente, sus dimensiones (fig. 3 núm. 31). La gran variedad de las piezas que se hallan dentro de las manifestaciones materiales de este yacimiento, asi como su larga ocupación humana, dificultan la asociación de este ejemplar a un contexto cultural preciso. Morán (Morán 1921 y 1942: 145-154) considera a esta punta como de la primera Edad del Bronce.

Dos puntas de flecha de este tipo proceden respectivamente de los Castros de Lara, en la provincia de Burgos y de Villasabariego, en la de León. Nada sabemos de sus entornos culturales, pero pueden, en efecto considerarse como pertenecientes a asentamientos anteriores que corres- 
ponderían a la Edad del Bronce. La primera es una punta de cobre o bronce, con aletas laterales pronunciadas que mide $4,5 \mathrm{~cm}$ de longitud y $2 \mathrm{~cm}$ de anchura (fig. 3, núm. 32). Considerada por su autor, como de la Edad del Bronce (Monteverde 1969: 225).

La segunda punta presenta aletas laterales pronunciadas, es de bronce y mide $5,6 \mathrm{~cm}$ de longitud y $1,2 \mathrm{~cm}$ de anchura (fig. 3, núm. 33). Su autor la sitúa en el segundo período de la Edad de Bronce (Luengo 1941: 137).

Por último, debemos citar la punta que de estas características procede de Molino de Garejo (Numancia), en la provincia de Soria, la cual se presenta asociada a cerámica campaniforme y a los Fondos de Cabaña, que fueron hallados al excavar la fortaleza romana. Esta punta, de cobre o bronce presenta aletas laterales marcadas y sus medidas son: $4 \mathrm{~cm}$ de longitud y $1,3 \mathrm{~cm}$ de anchura (fig. 3, núm. 34). Delibes (Delibes 1977: 52) la considera como correspondiente a un tipo más evolucionado que las puntas Palmela. Otro autor, Santaolalla (M. Santaolalla 1930: 912) la relaciona con la cultura del vaso campaniforme. Por último, Almagro (Almagro 1939: 146-148) la asocia a las invasiones célticas.

Todas estas puntas pueden constatarse en yacimientos de habitación y relacionarse a los contextos respectivos de los mismos, de forma semejante a las puntas de flecha procedentes de los yacimientos de la Submeseta Sur.

Por ello, creemos que no es aventurado el considerar a todas estas piezas presentes en yacimientos de ambas Submesetas, como pertenecientes al II milenio, es decir, a un Bronce que podriamos llamar "Pleno». Igualmente queda confirmada su asociación en ambos terrenos geográficos a yacimientos de habitación, sobre todo, y si tenemos en cuenta que no conocemos ningún ejemplar, hasta ahora, de estas características que pueda relacionarse con yacimientos funerarios.

En este sentido, debemos señalar, que si bién todas las puntas pueden encuadrarse en el mismo momento cronológico, no todas ellas pueden encuadrase en el mismo contexto cultural, pues, evidentemente, en la Submeseta Norte no hay nada semejante a la denominada Cultura de La Motillas, ni en la Submeseta Sur un yacimiento de las características culturales de los Tolmos, por ejemplo.

Del conjunto de puntas de flecha tratada, es la de Molino de Garejo el único ejemplar que puede relacionarse con un conjunto de materiales y con un tipo de yacimiento considerados como más antiguos. De cual- 
quier forma, es evidente, que no es ese el entorno cultural o uno de los entornos culturales "habituales" de estas piezas.

Del mismo modo, es la punta del depósito de Layna, el único ejemplar que puede relacionarse a un momento más moderno, cercano al Bronce Final. Este hecho puede interpretarse bajo dos prismas distintos, o bien el considerar que este ejemplar nos estaría marcando la pauta del uso y/o pervivencia de este tipo de puntas hasta las postrimerías de la Edad del Bronce, o bien el considerar la posibilidad de encuadrar este depósito en un momento anterior al atribuido por sus autores. $Y$ así podría ser, si nos atenemos al resto de los materiales que le conforman, dos puntas de flecha foliformes, cuyo tipo se halla presente en yacimientos de la Meseta, concretamente en algunos de los citados en estas páginas, con anterioridad al Bronce Final.

En cualquier caso, lo que es evidente, es que el auge y la utilización de estas puntas en ambas Submesetas fue en torno al II milenio, sustituyendo progresivamente a las puntas en uso más antiguas, como eran las tradicionalmente llamadas puntas Palmela. 


\section{BIBLIOGRAFIA}

Almagro, M., 1939: La cerámica excisa de la primera Edad del Hierro de la Península Ibérica. Ampurias l: 146-148.

CABRE, J., 1931: Instrumentos tallados en cuarcita en el argárico de la provincia de Ávila. Actas y Memorias de la Soc. Esp. de Antro. Etno. y Preh. ${ }^{a}$ 10: 285-324.

ColmenAREJo et alii, 1988: Actividades socioeconómicas de la Motilla de Santa Maria del Retamar: aproximación a su estudio. I Congreso de Historia Castilla-La Mancha 1: 351-360.

Delibes, G., 1977: El vaso campaniforme en la meseta norte española. Studia Archaeologica 46: 22-52.

Delibes, G., 1985: La Prehistoria del valle del Duero. Historia Castilla León 1: 36-52.

Fernández Miranda, M. y Balbín, R., 1971: Piezas de la Edad del Bronce en el Museo Arqueológico Provincial de Soria. Trabajos de Prehistoria 28: 289-296.

C. GALAN et alii (EP): La Motilla de Santa María del Retamar. Oretum 3.

JIMENO, A., 1978: Aportación al Bronce Final y Primer Hierro: Los Tolmos de Caracena, Soria. Rev. Inves. del Col. Univ. de Soria l: 51-66.

Jimeno, A., 1984: Los Tolmos de Caracena, Soria. Excavaciones Arqueológicas en España 134.

Luengo, J. M., 1941: El período Eneolítico y la Edad del Bronce en la provincia de León. Corona de Estudios que la Soc. Esp. de Antrop. Etno. y Preh. ${ }^{a}$ dedica a sus mártires: 137.

Martinez Santaolalla, J. M., 1930: Cerámica incisa y cerámica de la cultura del vaso campaniforme en Castilla la Vieja y León. Anuario de Preh. ${ }^{a}$ Madrileña I: 9-12.

Monteverde, J. L., 1969: La Colección Monteverde. Noticiario Arqueológico Hispano 10-11 y 12: 225.

Morán, C., 1921: El Cerro de El Berrueco. 
- 1942: Albores de Historia Salmantina. Guimaraes 52: 145-154.

NÁJERA, T. et alii, 1977: Excavaciones en las Motillas del Azuer y Los Palacios. Congreso Nacional de Arqueología XIV: 503.

- 1979: La Motilla del Azuer (Daimiel, Ciudad Real). Noticiario Arqueológico Hispano 6: 21.

Nieto, G. y Meseguer, J. S., 1980: El Cerro de La Encantada, Granáluta de Calatrava (Ciudad Real). Excavaciones Arqueológicas en España 113.

- 1983: El Cerro de La Encantada, Granátula de Calatrava. Noticiario Arqueológico Hispano 17: 9-41.

POYATO, $C$. et alii (EP): Memoria preliminar sobre las excavaciones en el yacimiento Calcolítico de El Castellón. Oretum 3.

Romero Salas, H. y Meseguer, J. S., 1988: El Cerro de El Cuco o de La Coronilla. Un yacimiento del área Suroriental de La Mancha. I Congreso de Historia Castilla-La Mancha 1: 335-342.

SÁNCHEZ JIMENEZ, J., 1947: Excavaciones y trabajos arqueológicos en la provincia de Albacete de 1942 a 1946. Poblado y necrópolis de La Peñuela. Informes y Memorias 15: 7-17.

- 1948: La cultura argárica en la provincia de Albacete. Notas para su estudio. Act. y Memo. de la Soc. Esp. de Antrop. Etno. y Preh. ${ }^{a}$ 23: 96-110.

Taracena, B., 1941: Carta Arqueológica de España, Soria, 122, 49 y 50. 